DOI: 10.20472/IAC.2019.046.016

\title{
LESZEK PYRA
}

The Pedagogical University of Cracow, Poland

\section{VIRTUE ETHICS AND ENVIRONMENT}

\begin{abstract}
:
One can definitely distinguish three major trends in a normative ethics: consequentialist, deontological and the one represented by virtue ethics. At the very beginning of the paper shortly a story of virtue ethics is reminded and then the status of the contemporary virtue ethics, which undergoes a spectacular revival nowadays, is briefly discussed. After this it is shown that an ethics of character can be modified in such way as to be applicable to an environment as such, and even that it may be normative in an effective way helping to solve some environmental problems with which both deontological and consequentialist theories have problems. In this context especially R. L. Sandler's project of a virtue-oriented environmental ethics is presented, analyzed and evaluated. His naturalistic, pluralistic and teleological project proposes some environmental virtues and vices especially referring to the environment. In such context, an axiology concerning the relation man-nature has been discussed. On the basis of some values appearing in nature virtue-oriented principles of right, adequate action has been formulated by Sandler which may, however, be hotly disputed. Then, concluding, I discuss some specific objections directed towards the possibility of developing an adequate virtue environmental ethics. It has been shown, I hope, that a project under discussion, a very interesting and certainly daring, is however still in statu nascendi, it has strong points when compared to anthropocentric (J.Passmore), biocentric (P.Taylor) and holistic (J.B.Callicot) standpoints in environmental ethics, but at the same time it also shows some weaknesses and therefore requires some further elaboration.
\end{abstract}

\section{Keywords:}

environment, virtue ethics, utilitarianism, deontology

JEL Classification: Y90 